\title{
Cardio-oncology: the new frontier of clinical and preventive cardiology
}

\author{
Sara Paris ${ }^{1}$, Luigi Tarantini ${ }^{2}$, Andrea Bonelli ${ }^{1}$, Alessandro Navazio ${ }^{3}$, Pompilio Faggiano ${ }^{1}$ \\ ${ }^{1}$ Cardiology Division, Spedali Civili and University of Brescia; ${ }^{2}$ Cardiology Division, Ospedale Civile "San Martino", \\ Belluno; ${ }^{3}$ Cardiology ASMN Hospital Unit USL Reggio Emilia-IRCCS, Reggio Emilia, Italy
}

\begin{abstract}
Even if cancer and cardiovascular diseases are considered two distinct diseases, an intricate interconnection between these conditions has been established. Increased risk of malignancy has been identified in patients with cardiovascular disease, as well as a greater propensity to the development of cardiovascular diseases has been observed in patients with cancer. The development of cardiotoxicity following exposure to certain anticancer drugs only partially explains this relationship. Shared risk factors and common pathogenic mechanisms suggest the existence of a common biology and a complex interplay between these two conditions. Due to improving longevity and therapeutic advances, the number of patients affected or potentially at risk of developing these two diseases is constantly increasing and currently, several drugs against cancer from anthracyclines to checkpoint inhibitors, can also cause a wide range of unexpected cardiovascular side effects. Management of these issues in clinical practice is an emerging challenge for cardiologists and oncologists, and led to the development of a new dedicated discipline called cardio-oncology. Surveillance and prevention strategies as well as interventions to
\end{abstract}

Correspondence: Pompilio Faggiano, Cardiology Division, Spedali Civili, Piazzale Spedali Civili 1, 25123 Brescia, Italy.

Tel. +39.030.3995571.

E-mail: cardiologia@pompiliofaggiano.it

Authors' contributions: All the authors made a substantive intellectual contribution. All the authors have read and approved the final version of the manuscript and agreed to be accountable for all aspects of the work.

Conflict of interest: The authors declare that they have no competing interests, and all authors confirm accuracy.

Keywords: Cardio-oncology; cardiotoxicity; cancer; cardiovascular diseases; risk factors.

Received for publication: 29 Apil 2020.

Accepted for publication: 2 May 2020.

${ }^{\circ}$ Copyright: the Author(s), 2020

Licensee PAGEPress, Italy

Monaldi Archives for Chest Disease 2020; 90:1348

doi: 10.4081/monaldi.2020.1348

This article is distributed under the terms of the Creative Commons Attribution Noncommercial License (by-nc 4.0) which permits any noncommercial use, distribution, and reproduction in any medium, provided the original author(s) and source are credited. reduce cardiovascular risk and prevent cardiotoxicities are the primary objectives of cardio-oncology.

In this review, we explore the etiopathogenesis common to cardiovascular disease and cancer and the complex interplay between them. We also report the main characteristics of the drugs responsible for cardiotoxicity, highlighting the available strategies for optimal patient management based on a multidisciplinary approach in the cardio-oncology setting.

\section{Introduction}

Cardiovascular disease (CVD) and cancer are the two leading causes of mortality and morbidity worldwide [1]. The burden of both illnesses is expected to increase as the population grows older and therapies enhance longevity.

Emerging evidence [2-6] suggests a bidirectional relationship between CVD and cancer. Shared risk factors, genetics and cellular pathways underpin a common biology, suggesting an overlap between these two entities.

It is estimated that approximately $40 \%$ of cancers are linked to common modifiable factors as smoking, alcohol abuse, sedentary lifestyle, obesity, unhealthy diet [7]. The detrimental prognostic importance of such factors, well known in traditional practice of cardiology, has relevance even in the cardio-oncological field. Inadequate management of cardiovascular risk factors increases the risk of cardiotoxicity of cancer therapies and reduces the probability of healing from cancer. The increase in long-term cancer survival also shows that, regardless of the baseline value, some cancer treatment can worsen the CV risk profile thus increasing the chance of a second tumor or a cardiovascular event in the following years $[8,9]$; therefore strategies to improve their prevention and treatment are global priorities.

Starting from these shared understanding, the collaboration between oncologists and cardiologists is essential, with the goals of balancing the potential adverse influence of one disease on the other, implementing the strategies to reduce the incidence of both CVD and cancer and their clinical impact.

\section{Shared biology, genetic and cellular molecular pathways}

\section{Inflammation and oxidative stress}

Chronic inflammation is a common thread between a variety of diseases, including both CVD and cancer [10,11]. Inflammation is a unifying mechanism induced by numerous conditions such as obesity, hypertension, hyperglycemia, hypertriglyceridemia, 
microbial and viral infections, allergen exposure, radiation, toxic chemicals, alcohol consumption, tobacco use, and other chronic and autoimmune diseases [12].

It is known that inflammation participates pivotally in the pathogenesis of atherosclerosis and its complications and it could play a major role to trigger plaque rupture/erosion, which is the most common phenomenon responsible for acute coronary syndrome $[11,13]$. Atherosclerosis, the major cause of CVD, is characterized by a chronic inflammation in large and middle-sized arteries, where activated immune competent cells are abundant $[13,14]$. Many risk factors for CVD (hypertension, hyperlipidemia, tobacco use, and insulin resistance) trigger atherosclerosis by promoting adhesion of endothelial cells and stimulation of leukocyte attachment to blood vessel walls [11].

It is well known that atherogenesis is characterized by continuous accumulation of lipids and inflammatory cells in the arterial intima. The inflamed microenvironment of the plaque is rich in pro-inflammatory cytokines such as interleukin-1 (IL-1), tumor necrosis factor- $\alpha$ (TNF- $\alpha$ ), and interferon- $\gamma$ (IFN- $\gamma)$ [15]. The abundance of oxidized low-density-lipoprotein cholesterol (LDL) and reactive oxygen species (ROS) leads to the activation of inflammatory signaling and gene expression cascades including nuclear factor-kB (NF-kB) [16]. Under conditions that favor a state of chronic low-grade inflammation, such as obesity and hypertension, dysregulation of macrophage polarization between the proinflammatory M1 and anti-inflammatory M2 phenotypes promotes cardiac injury [17]. In patients with heart failure (HF), inflammation has also been linked to disease development, progression, complications and outcomes [18].

The hypothesis of a relationship between inflammation and cancer arises from the finding of leukocytes within the neoplastic tissue, suggesting that together with gene mutations and DNA instability, chronic inflammation is a necessary process for tumor progression and metastasis [19,20]. Furthermore, the association between some chronic infections and cancer has been established, such as human papilloma virus and cervical cancer [21], Helicobacter pylori and stomach cancer [22], Epstein Barr virus and lymphomas [23]. Several cancer types are frequent in chronic inflammatory diseases, among them celiac disease and small bowel lymphomas [24]. Inflammation promotes carcinogenesis and tumor progression, inducing DNA damage and chromosomal instability, enhancing tumor cell proliferation and resistance to apoptosis and stimulating angiogenesis [10]. The interaction between malignant cells and a chronically inflamed extracellular microenvironment activates a wide array of dysregulated intracellular signaling pathways and transcription factors implicated in tumor growth, angiogenesis, and metastasis [25].

High levels of innate cytokines, as evident in chronic inflammation, may promote tumor development [26,27]. Reactive oxygen species (ROS) and reactive nitrogen species (RNS) can induce DNA damage and modulate the expression of oncogenes and tumor suppressor genes [28]. Two central pathways of inflammation, Wingless-INT (Wnt) and adenosine 5' monophosphate-activated protein kinase (AMPK), play a role also in the pathogenesis of atherosclerosis and endothelial dysfunction, as well as in cancer [15]. Slug/Snai2 is a transcription factor with a well-described role in cancer progression [29]. New evidence suggests that this factor may contribute to inflammation in dedifferentiated smooth muscle cells and, potentially, atherosclerotic plaque formation and instability. Slug/Snai2 has also been related to impaired cholesterol metabolism [30].

In this setting, biomarkers of inflammation seem to be related to both CVD events and cancer. IL- 6 is one of the most important.
This cytokine is related to hypertension and hepatic production of C-reactive protein (CRP) [31]. Moreover, it represents the terminal effector of inflammation in HF [32]. IL-6 has been reported to be involved in the inflammation associated tumorigenesis and may promote tumor growth by inhibiting apoptosis and inducing tumor angiogenesis [33,34]. IL-6 is a strong predictor of all-cause, cardiovascular and cancer-related mortality [35]. IL-1 $\beta$ signaling is correlated with cardiac remodeling and dysfunction. For this reason, this mediator is particularly important in HF [32]. IL-1 $\beta$ generated in the course of chronic inflammation supports tumor development [26]. In particular, it could play a role in case of clonal hematopoiesis of indeterminate potential (CHIP), as described below [36].

Common genetic factors in the pathophysiology of both disease have also been identified, such as aberrant activation of LRP6, TCF7L2 polymorphism, DYRK1B mutations, methylenetetrahydrofolate reductase (MTHFR) C677T polymorphism [15].

\section{Metabolic disorders promoting both CVD and cancer}

\section{Obesity and metabolic syndrome}

According to epidemiologic data, up to $20 \%$ of malignancies could be related to weight, weight gain and obesity [37]. The risk of cancer appears to rise with increasing BMI, where cancer risk was increased by $12 \%$ with a BMI of 27.5 to 29.9 and up to $70 \%$ in those with a BMI greater than $40 \mathrm{~kg} / \mathrm{m}^{2}$ [38]. Each $1 \mathrm{~kg} / \mathrm{m}^{2}$ of excess weight increases the risk of cancer by $21 \%$ [39]. Bariatric surgery for severe obesity is associated with long-term weight loss and reduced overall mortality; in particular, cancer mortality is reduced by approximately $60 \%$ [40]. Evidence supports a causal link between overweight and obesity and risk of cancer incidence at several sites, including pancreas, esophagus, colorectum, renal cell, liver and cholangiocarcinoma, thyroid, postmenopausal breast and endometrial cancers, among others [41]. Recent epidemiological evidence, furthermore, highlights that obesity in the first decades of life is associated with the anticipation of obesity-related cancer (colon, pancreas) in the following decades of early adult life (40-50 yrs) emphasizing the important role of this treatable risk factor [42-45].

Obesity, and visceral obesity in particular, is a condition characterized by a proinflammatory and prothrombotic state, insulin resistance and atherogenic dyslipidemia [46-48]. Adipose tissue becomes dysfunctional, promoting a pro-inflammatory, hyperlipidemic and insulin resistant environment that also contributes to type 2 diabetes mellitus (T2DM) [49,50]. Accordingly, obesity has been classified as an independent risk factor for CVD [51,52]. The increased cardiovascular risk has also been established in young people [53]. Furthermore, there is a well-documented association between obesity and heart failure [32]. In addition, different hormones and pro-inflammatory cytokines, also referred to as adipokines, are produced by the adipose tissue, several of which have antiapoptotic and proangiogenic properties. Obesity alters the expression of adipokines, such that predominantly proinflammatory cytokines are released, including TNF-alfa, IL-6, IL-1 $\beta$ and Monocyte chemotactic protein-1 (MCP-1) [49]. These, in addition to promoting fat storage, also have oncogenic properties [12]. High concentrations of estrogen are commonly seen in obese people. Estrogen signaling and aromatase expression in the breast of obese women are often impaired, promoting cancer formation and pro- 
gression [54]. Leptin is an adipocyte-derived hormone. Increased circulating leptin is frequent in obesity and independently associated with insulin resistance and CVD [55]. The mitogenic and antiapoptotic effects of leptin have been described in various cancer types. Leptin also induces cancer progression, cell migration and invasion [56]. It is closely related to hepatocellular carcinoma [57], but also prostate cancer [58], breast and gynecologic cancer [59]. There is also a plausible hypothesis that the huge adverse effect of obesity on cancer burden might be mediated largely by insulin [60]. High levels of insulin-like growth factor-1 (IGF-1) are often found in obesity and in the metabolic syndrome and are associated with tumor growth, as outlined below $[61,62]$.

In addition to biochemical mechanism linking obesity to cancer incidence, obesity may indirectly worsen cancer mortality through the effect of chemotherapy on cardiovascular system. The risk of developing cardiotoxicity from cancer therapy in obese patients is higher due to reduced cardiac reserve and associated cardiovascular morbidities (Figure 1) [39].

\section{Diabetes mellitus}

The close correlation between diabetes and CVD is wellknown. Diabetes is associated with an early, accelerated and widespread atherosclerosis. Hyperglycemia and insulin resistance are the two major hallmarks of diabetes responsible for CVD. The common underlying mechanism appears to be the increased ROS production in diabetic cardiomyocytes [63]. Hyperglycemia may trigger smooth muscle cells proliferation and migration through the expression of many growth factors, especially IGF-1 [64].
Diabetes may influence the neoplastic process by several mechanisms, including hyperinsulinemia (either endogenous due to insulin resistance or exogenous due to administered insulin or insulin secretagogue), hyperglycemia, or chronic inflammation [65]. Insulin-like signaling systems are important to control cell proliferation and survival [60]. Tumor cells express both insulin and IGF receptors and multiple signaling pathways are activated after insulin receptors or IGF-I receptors interact with their ligands [65]. Once activated, these signaling pathways may induce proliferation, protection from apoptotic stimuli, invasion, and metastasis. It has been reported a modestly increased risk of prostate cancer, premenopausal breast cancer and colorectal cancer in people with high circulating levels of IGF-1 [66,67]. Hyperinsulinemia could also promote carcinogenesis indirectly, reducing hepatic production of IGF binding protein and consequently increasing the levels of circulating free bioactive IGF-I [68]. Moreover, elevated circulating insulin causes a reduction in the hepatic synthesis and blood levels of sex hormone binding globulin, leading to increases in bioavailable endogenous sex steroid [69].

Accordingly, the risk of postmenopausal breast, endometrial, and possibly other cancers is incremented [65]. Inflammation further helps through enhancing insulin resistance to the complex interplay of cancer and CVD [70].

\section{Hyperlipidemia}

Hypercholesterolemia, in particular high level of LDL associated cholesterol, fulfills all criteria required to consider a traditional risk factor as a causative agent of atherosclerosis [71]. In fact,

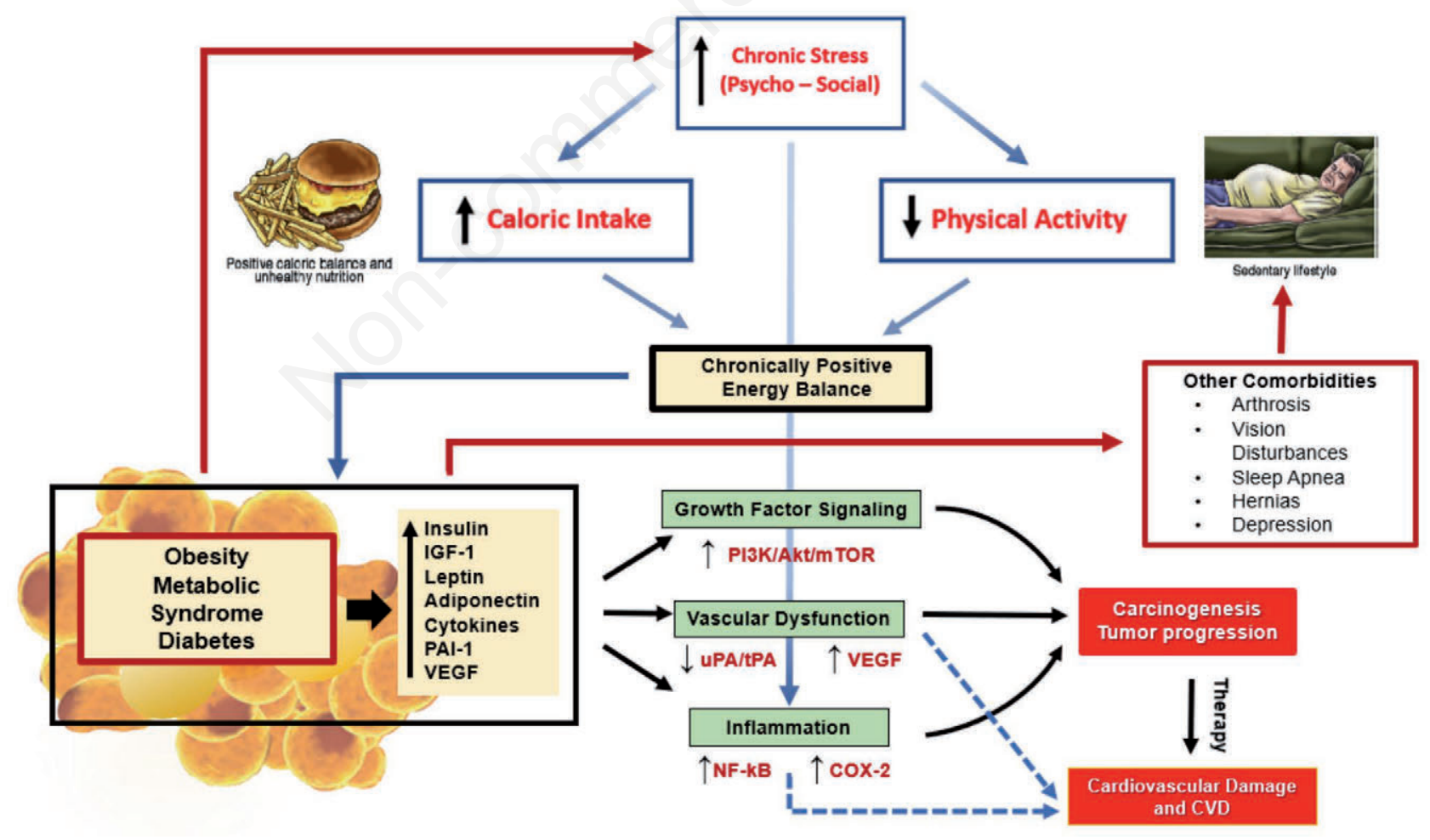

Figure 1. Obesity, sedentary behavior and unhealthy diet: a vicious circle promoting the development of cancer and cardiovascular diseases. IGF-1, insulin like growth factor-1; PAI-1, Plasminogen activator inhibitor-1; VEGF, vascular endothelial growth factor; PI3K/AKT/mTOR, pathway involving phosphatidylinositol 3-kinases, AKT serine-threonine kinase, and the mammalian target of rapamycin; uPA/tPA, urokinase-type (uPA) and the tissue-type (tPA) activators of plasminogen; NF-kB, nuclear factor kappa-lightchain-enhancer of activated B cells; COX-2, Cyclooxygenase-2; CVD, cardiovascular disease. See the text for details. 
several mechanisms, including oxidative modification of the lipoprotein and formation of foam cells, contribute to atherogenesis; oxidized LDL was found to have biological effects on the vessel wall, including stimulation of cytokine production, inhibition of endothelial cell vasodilator function, and stimulation of growth factor production [72].

Several epidemiological studies suggested that high cholesterol levels are associated with increased risk of developing cancer [73]. Cholesterol is metabolized to active derivatives including cholesterol oxidization products (COP), known as oxysterols, which have been shown to alter cellular proliferation [73]; 27-hydroxycholesterol (27-OHC) is the most abundant oxysterol in the plasma and has been shown to be involved in the pathogenesis of several cancers including breast [74], and prostate cancer [75]. In contrast, 27-OHC reduces cell proliferation in colorectal cancer cells, suggesting a variable effect according to organ affected [73]. Moreover, it has been described a relation with atherosclerosis via proinflammatory processes mediated by estrogen receptor alpha [76].

\section{Hypertension}

In case of high blood pressure, the presence of inflammation, oxidative stress, neurohormonal activation and autonomic influences contributes to CVD and to cancer as well. The increase in oxidative stress may activate genes involved in generating an inflammatory response that, in the presence of hyperlipidemia, leads to the formation of atherosclerotic plaque [72].

In hypertensive subjects an increase in vascular endothelial growth factor (VEGF) levels is observed, due to angiotensin II [77]. VEGF plays a crucial role for new blood vessel formation, a fundamental step for the development and growth of the tumor [78]. Elevated blood pressure (BP) was significantly associated associated with incident cancer in men (hazard ratio per $10 \mathrm{mmHg}$ increment: 1.07 [95\% CI: 1.04-1.09]) and with cancer mortality in both sexes (HRs per 10-mmHg increment of 1.12 [95\% CI: 1.08 1.15] for men and 1.06 [95\% CI: 1.02-1.11] for women) [79]. Again, hypertension increases the risk of kidney cancer in both sexes [80]. In particular, it has been described a close connection with an increased risk of mortality from renal cell carcinoma [81]. In men, hypertension is related to prostate cancer as part of the metabolic syndrome. Higher risk for developing endometrial and breast cancer has been described in hypertensive women [80].

\section{Unhealthy lifestyle}

Figure 2 shows the proportions of cancers attributable to the modifiable causes described below [7]. The population attributable fraction (PAF) represents the contribution of a risk factor to the burden of disease or death and corresponds to the proportional reduction in population disease or mortality burden that would occur if exposure to a risk factor was eliminated [7].

\section{Tobacco}

Smoking is a well-known shared risk factor for CVD and cancer. Tobacco usage promotes atherosclerosis through exposition to cigarette smoke causing endothelial cell activation, dysfunction, injury, and death, leading to storage of lipids and inflammatory cells, as well as reducing the nitric oxide. Activated inflammatory cells, adhesion molecules and spontaneous platelet aggregation support the shift toward a procoagulant state and consequently the formation of rupture-prone plaques [82]. On the other hand, repetitive injury to squamous cell epithelium enhances carcinogenic effect. Nicotine, a highly addictive substance, can inhibit apoptosis and enhance angiogenesis [82]. There is broad agreement that cigarette smoking causes cancers at a minimum of 12 different sites, including lung, oral cavity, pharynx, esophagus, pancreas, larynx, urinary bladder [83]. Mortality among current smokers is 2 to 3 times as high as that among persons who never smoked. Moreover, it has been described that male smokers are at higher risk for death from prostate cancer and female smokers are at higher risk for death from breast cancer [84].

\section{Alcohol}

Moderate alcohol consumption seems to have a cardioprotective effect in subjects free from CVD. The linkage is described by a J-shaped dose effect-curve: in case of excessive alcohol intake all-cause mortality and cardiovascular events are increased [12]. Larger amounts can cause dilated cardiomyopathy and heart failure [85]. Several potential cardioprotective effects of low alcohol doses have been hypothesized, such as decreased inflammation, decreased platelet aggregation and function, reduced myocardial ischemia-reperfusion damage, effects on coagulation factors, endothelial events, elevated high-density lipoprotein (HDL) cholesterol levels and effect on anti- and proapoptotic pathways [12].

The effect of alcohol on cancer development appears to be modulated by polymorphisms in genes encoding enzymes for ethanol metabolism (e.g., alcohol dehydrogenases, aldehyde dehydrogenases, and cytochrome P450 2E1), folate metabolism, and DNA repair [86,87]. Moreover, acetaldehyde, the main metabolite of ethanol, may exert genotoxic effect [86]. Alcohol intake has been linked to hepatocellular carcinoma (HCC). The relationship could be a direct toxic effect, or an indirect one, mediated by cirrhosis, a predisposing factor for HCC [88]. Causal link has been established also between alcohol and cancers of the oral cavity, pharynx, larynx, esophagus (squamous cell carcinoma), colorectum and breast (pre- and post-menopause) $[89,90]$.

\section{Unhealthy diet}

Increased cardiac risk has been established for an unhealthy diet, which is common in western countries, and is characterized by a high amount of saturated fat, red meat, sugar and processed food [39,91]. Evidences indicate that higher intake of most dietary saturated fatty acids (SFAs) increases blood levels of LDL cholesterol and the LDL to HDL ratio, resulting in an increased risk of coronary heart disease (CHD) [92,93]. Replacing 5\% of energy intake from saturated fats with equivalent energy intake from either polyunsaturated fatty acids (PUFAs), monounsaturated fats (MUFAs), or carbohydrates from whole grains was associated with $25 \%, 15 \%$, and $9 \%$ lower risk of CHD, respectively [92]. Excessive intake of dietary trans fatty acids (TFA) is an important risk factor for cardiovascular events as well as a risk factor for cancer and diabetes [94]. Direct carcinogens, such as aflatoxins and nitrosamines, may be present in food and can act directly on DNA, causing mutations, deletions and insertions [31].

On the contrary, fruit and vegetable intakes are associated with reduced risk of CVD, cancer and all-cause mortality [95]. Higher whole grain intake is associated with a reduced mortality, especially deaths due to CVD [96].

Dietary fiber and fruit and vegetable intakes have been shown to lower blood pressure, cholesterol levels, inflammation and platelet aggregation, and to improve vascular and immune function [95]. Antioxidant, antibacterial, and antiviral effects as well as positive modulation on steroid hormone concentrations and hormone metabolism have also been observed [97]. High-fiber foods may 
have a beneficial effect on gut microbiota [98]. Antioxidants in fruit and vegetables may neutralize reactive oxygen species and reduce DNA damage [97]. In this regard, a diet rich in vegetables and whole grains such as the Mediterranean diet is associated with a lower incidence and mortality from breast cancer $[99,100]$.

\section{Sedentary lifestyle}

Several large studies have demonstrated that mortality is inversely related to the level of physical activity $[101,102]$. In particular, physical activity is associated with a $20 \%$ to $30 \%$ lower risk of CHD [103]. Regarding the amount of physical activity required to reduce CVD risk, it has been reported that $150 \mathrm{~min}$ of weekly moderate activity reduces mortality by $14 \%, 300$ min by $20 \%$ [104]. A similar inverse dose-dependent association between physical exercise and risk of HF has also been described [105]. In addition to cardioprotective effects, exercise promotes a modest reduction in the incidence of prostate, breast, bladder, esophageal, kidney, and endometrial cancers [31,106]. Physical activity also reduces cancer mortality and recurrence in cancer survivors [107,108]. For each 15-min increment of daily physical activity, cancer mortality decreases by $1 \%$ [109]. The underlying mechanisms likely relates to reduction in obesity, metabolic syndrome, diabetes, hypertension and hyperlipidemia. Furthermore, in patients with cancer, exercise prevents cardiac-related drug toxici-

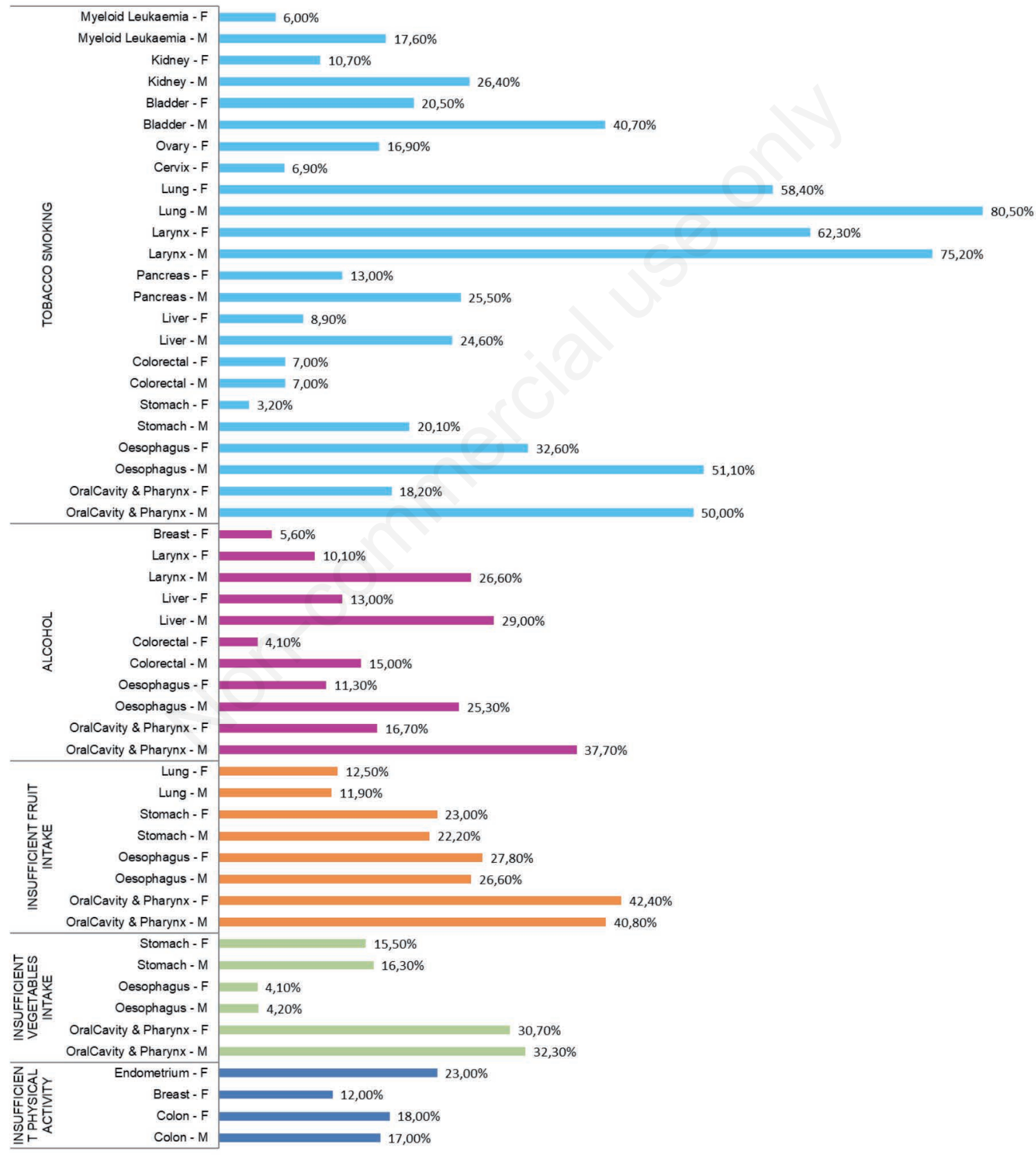

Figure 2. Median of population attributable fractions, expressed as a percentage (PAF\%), reported for modifiable risk factors associated with specified cancers. F, female; $M$, male. See the text for details. 
ty thanks to better cardiovascular health and greater cardiac reserve [39].

\section{Development of malignancy in patients with CVD: "the Reverse Cardio-Oncology"}

Due to advancements in management of ischemic heart disease and chronic heart failure, the prognosis of patients affected has improved significantly, with more patients surviving for an extended time, thus increasing the importance of detection and treatment of non-cardiac diseases. It has been described that patients with HF have an increased risk of cancer and their prognosis is worse compared with that of cancer patients without HF [2,3]. Moreover, increased risk of malignancy was identified in patients with HF after myocardial infarction (this trend was seemingly more evident among patient with reduced left ventricular ejection fraction) [110], patients undergoing cardiac interventions or procedures, and patients after a thrombotic event [111]. The specific mechanism for this relationship has not been established.

As already described above, CVD and cancer both share proinflammatory pathways or impaired cellular metabolic profiles [12]. It has also been hypothesized that impairment in immunity after HF development predisposes to higher cancer risk [110]. In the context of myocardial infarction, necrotic cells release danger sig- nals, resulting in an intense inflammatory response [112]. In case of cardiac damage, tissue hypoxia and shear stress may trigger epigenetic response. Epigenetic mechanisms, such as DNA methylation, histone modifications, and RNA-based mechanisms, are also extensively associated with cancer, including colorectal, breast, and various other malignancies [113]. Tissue hypoxia in patients with CVD can also stimulate tumor growth and progression via HIF-1 pathway [111]. Higher incidence of cancer was reported among ischemic stroke survivors $(20 \%$ in 1 year and $40 \%$ at 2 years) [114]. Hypercoagulability secondary to thrombin activation can promote angiogenesis, tumor growth and the development of metastasis in these patients [111].

Clonal hematopoiesis (CHIP), is defined as the presence of an expanded somatic blood-cell clone without other evidence of hematologic malignancy, is a common condition among older persons and is associated with an increased risk of hematologic neoplastic disease [115]. One of the most frequently abnormality encountered in hematopoietic clones is represented by mutation in Ten-Eleven Translocation-2 (TET2) genes. TET2 deficiency is associated with elevated concentration of IL-1 $\beta$ and with the development and poor prognosis of heart failure [36]. The presence of CHIP in peripheralblood cells was also linked with almost a doubling of the risk of coronary heart disease in humans and with accelerated atherosclerosis in mice [115]. Somatic mutations in hematopoietic stem cells represent a common path for cancer and CVD [36].

Regarding the pharmacological treatment of CVD and cancer

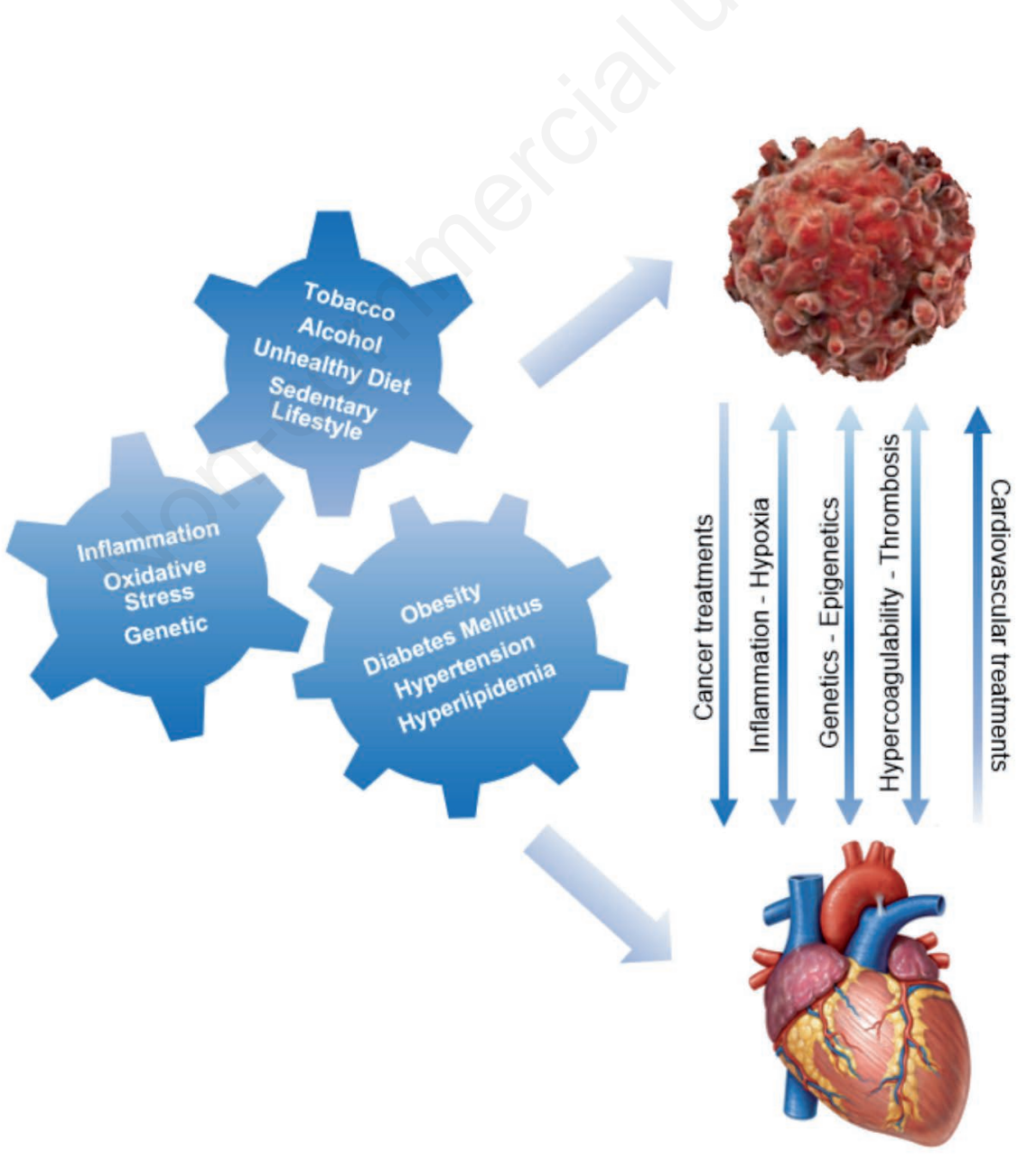

Figure 3. Dynamic interplay between cancer and cardiovascular disease. See the text for details. 
development, data are inconclusive and conflicting. There is currently no evidence that cardiovascular medications are closely linked to an increased risk of cancer. It has been suggested an increased risk of cancer development in case of angiotensin-converting enzyme inhibitors (ACE-Is) and angiotensin receptor blockers (ARBs) combination [116]. Individually, the use of ACEIs or ARBs has been linked to a $6 \%$ decreased incidence of colon cancer [117]. Instead, in the Life After Cancer Epidemiology (LACE) Study cohort, ACE-Is exposure was associated with breast cancer recurrence [118]. Although still limited, evidence suggests that increasing exogenous insulin dose is associated with an increased cancer risk in people with type 2 diabetes treated with insulin monotherapy [119].

Thus, need exists to update the current understanding of the potential effect on risk of future cancer of cardiovascular medications.

\section{Development of CVD in patients with cancer}

On the basis of shared risk factors, the prevalence of heart disease in patients with cancer could be increased also at the time of cancer diagnosis, before treatment begins. It has been observed that calcium scores of the coronary arteries are higher in a cohort of patients with breast cancer pre-radiotherapy than in age-matched healthy controls, suggesting that breast cancer patients may also bear a higher risk of developing coronary heart disease independently from treatment [120]. Cancer cells can induce a proatherosclerotic, prothrombotic and hypercoagulable state, due to production of various pro-inflammatory cytokines, increased concentration of LDL into vascular intima, and increased levels of coagulation molecules, leading to newly unstable formed plaques [121]. On the other hand, cancer is also a prothrombotic disease, favoring thromboembolic events as deep vein thrombosis and pulmonary embolism [122].

Cardiotoxicity is defined as the 'toxicity that affects the heart', including a direct effect of cancer drugs on the heart but also an indirect effect due to enhancement of hemodynamic flow abnormalities or due to thrombotic events $[123,124]$. As a consequence, cardiac adverse events, such as HF, hypertension, myocardial infarction, thromboembolism, pericardial effusion, QT prolongation, and bradycardia, may cause premature discontinuation of effective oncologic treatments, thus becoming an obstacle in the battle against cancer [125]. Genetic and epigenetic factors may influence the cardiotoxicity susceptibility (Figure 3) [123].

\section{Management strategies}

\section{Prevention of CVD and cancer: better safe than sorry}

In 2010 the American Heart Association has defined the concept of ideal cardiovascular health, according to 7 health behaviors, including nonsmoking, physical activity at goal levels, body mass index $<25 \mathrm{~kg} / \mathrm{m}^{2}$, healthy dietary intake, untreated total cholesterol $<200 \mathrm{mg} / \mathrm{dL}$, untreated blood pressure $<120 /<80 \mathrm{~mm} \mathrm{Hg}$, and fasting blood glucose $<100 \mathrm{mg} / \mathrm{dL}$ [126]. It has been demonstrated that achieving the goals for a higher number of ideal health parameters is associated with more favorable health outcomes [127]. In this regard, in the Atherosclerosis Risk in Communities (ARIC) Study, a strong inverse relationship was identified between the number of ideal health metrics met at baseline and incident CVD over 20 years of follow up [128]. Additionally, obedience to the 7 ideal health metrics resulted also linked with lower cancer incidence. Participants meeting goals for at least 6 of the 7 health metrics had 51\% lower risk of incident cancer [129]. Accordingly, the identification and management of risk factors allow to reduce both CVD and cancer. As is well known, prevention is better than cure.

\section{Management of cancer patients: the role of cardio-oncology}

For many malignancies, the disease has shift from an incurable illness to a chronic condition. Due to the aging of the population, a common occurrence of risk factors, and the administration of cancer therapies to more elderly individuals with pre-existing CVD, it is increasingly likely that a patient may simultaneously have both CVD and cancer [123]. An optimal management of these two diseases is not anymore linked to survival prospects, but also to quality of life during the years earned.

In this setting, cooperation between oncologists and cardiologists is essential to ensure optimal patient management, adopting a holistic and patient-tailored approach.

As previously mentioned, cardiovascular comorbidity can adversely affect cancer outcome. Patients with CVD and/or cardiac risk factors may receive less aggressive cancer treatment. Early identification by the oncologist of patients at risk for cardiotoxicity and optimal management of cardiovascular problems by cardiologists, should be the initial strategy in the development of personalized antineoplastic therapies $[123,130]$.

On the other hand, the appropriate treatment of CVD may also be affected by the presence of cancer. In coronary heart disease patients receiving dual antiplatelet therapy (DAPT), the high risk of bleeding due to the presence of cancer could lead to the withdrawal of aspirin or other antiplatelet drug, with a potential increase of risk of new cardiovascular events. In presence of an acute coronary syndrome, a difficult decision may have to be taken between conservative medical management or early coronary angiography and revascularization [131,132]. In patients with severe symptomatic aortic valve stenosis and cancer, not infrequent in older population, the timing and the choice between aortic valve intervention (surgical or transcatheter) and conservative medical treatment is closely influenced by the type and site of cancer, stage, and outcome [133]. Even in these cases the role of a cardio-oncology team could be decisive. Provide the best treatment with the least possible side effects is always an important task.

\section{Risk stratification and early identification of high-risk patients}

The first step is to stratify the risk of cancer patients according to the presence of established atherosclerotic vascular disease, or other cardiac diseases, diabetes mellitus, chronic kidney disease and traditional cardiovascular risk factors (Table 1) [134,135]. HF and/or arrhythmias should also be investigated, especially atrial fibrillation [123]. Identification of high-risk patients is essential in order to apply proper arrangements, including optimization of cardiovascular risk factors and preexisting disease, planning a more stringent follow up during therapy [136]. Adverse effects may occur even after years, therefore long-term surveillance of cancer survivors is mandatory [137]. Several antineoplastic medications potentially affect the cardiovascular system (Table 2) [123,138-145]. Radiotherapy can also cause cardiovascular damage [146]. Hypertension is the most common comorbidity in cancer patients. As underlined before, pre-existing hypertension is known to increase the risk of other cardiac adverse events, in particular HF [80]. Furthermore, CAD, hypertension, and diabetes are the strongest predictors of left 
Table 1. Risk stratification of high risk patients. See the text for details.

\begin{tabular}{l} 
Risk factors for developing cardiotoxicity \\
Young (<18 years) or advanced age ( $>50$ years for trastuzumab; $>65$ years for anthracyclines) \\
Lifestyle risk factors \\
- $\quad$ Smoking \\
- $\quad$ High alcohol intake \\
- $\quad$ Sedentary habit \\
\hline Established cardiovascular disease \\
- $\quad$ Arterial hypertension \\
- $\quad$ Heart failure (with either preserved or reduced ejection fraction) \\
- $\quad$ Asymptomatic LV dysfunction (LVE < $50 \%$ or B-type natriuretic peptide $>100$ pg/ml, or N-terminal pro-B-type natriuretic peptide > 400 pg/ml with no \\
$\quad$ alternative cause) \\
- $\quad$ CAD (previous myocardial infarction, angina, PCI or CABG, myocardial ischemia) \\
- Moderate to severe valvular heart disease with LV hypertrophy or LV impairment \\
- $\quad$ Hypertensive heart disease with LV hypertrophy \\
- $\quad$ Hypertrophic cardiomyopathy \\
- $\quad$ Dilated cardiomyopathyRestrictive cardiomyopathy \\
- $\quad$ Cardiac sarcoidosis with myocardial involvement \\
- $\quad$ Significant cardiac arrhythmias (e.g. atrial fibrillation, ventricular tachyarrhythmias)
\end{tabular}

Diabetes mellitus

Obesity

Hypercholesterolemia

Previous cardiotoxic cancer treatment:

Prior anthracyclines use

Prior radiotherapy to chest or mediastinum

Simultaneous chemotherapy with other potential cardiotoxic agents

LV, left ventricular; $\mathrm{LVEF}$, left ventricular ejection fraction; $\mathrm{CAD}$, coronary artery disease; $\mathrm{PCI}$, percutaneous coronary intervention; $\mathrm{CABG}$, coronary artery bypass graft.

ventricular dysfunction secondary to anthracycline cardiotoxicity $[124,136]$. Again CAD, hypertension, obesity, and smoking are well-known risk factors for developing left ventricular dysfunction among patients with breast cancer receiving trastuzumab [147]. Smoking cessation is extremely important, so as a tight glycemic control in diabetic patients [146].

\section{Recommended cardiovascular drugs in patients on cancer treatment}

Beta-blockers and ACE-Is have been reported to be protective against cardiac toxicity and are recommended in high-risk patients or in patients who develop cardiotoxicity [146]. The prophylactic use of these medications in patient planned for chemotherapy, radiation, or targeted therapy has also been hypothesized [148]. Ivabradine may be a possible additional treatment for selected patients [149]. The effects and possible benefits of sacubitril/valsartan need to be investigated in large scale studies [150].

It is widely recognized that treatment of dyslipidemia is key for cardiovascular prevention, both primary and secondary [151]. In addition to potent LDL-cholesterol lowering, statins have several pleiotropic effects, such as anti-inflammatory and antioxidant properties. A potential anti-cancer role for statins is also emerging, but further studies are needed to identify its therapeutic potential $[12,15]$. Evidence shows improvement in cancer-specific and overall-survival in cancer patients who are on statins either before or after the time of diagnosis $[152,153]$. Recently, it has been highlighted that approximately $50 \%$ cancer survivors remain untreated although they are eligible for statin therapy. This underlines the need for greater attention to prevent atherosclerotic CVD among these patients $[154,155]$. Similarly to statin, potential beneficial effects on cancer recurrence have been identified also for aspirin and for metformin, due to their positive effects on AMPK $[15,156]$. Randomized dedicated trials are ongoing [156,157]. Anti-inflammatory medications - in particular, statins, colchicine, and aspirin - show also great promise for the prevention of radiation-induced CVD. Nonetheless, direct large-scale studies are called for [158]. In addition to drugs, exercise seems to counteract the negative effects due to chemotherapy, such as fatigue, pulmonary and immune system dysfunction, lymphoedema and toxicity for the heart $[159,160]$. Furthermore, higher cardiorespiratory fitness (CRF) is independently associated with lower risk of cancer mortality in men with documented CVD who develop cancer, suggesting that tailored exercise rehabilitation programs aimed at encouraging regular physical activity may improve the prognosis of these patients $[161,162]$. In this regard, mobile health technology, through the use of devices and applications, has the potential to become a powerful healthcare tool [163]. A classification of cancer therapy-induced myocardial toxicity has been proposed by the Royal Brompton Hospital. Depending on the degree of severity, for each of the 6 classes identified, a management strategy has been defined (Table 3) [164].

Previous data have shown that administration of cardiovascular treatments in patients exposed to cardiotoxic drugs can reduce symptomatic CHF and left ventricular ejection fraction (LVEF) and may allow at least partial recovery in whom developing left ventricular systolic dysfunction (LVSD) [165]. In this regard, in a cohort of 2625 patients receiving anthracycline-containing therapy, the overall incidence of cardiotoxicity was $9 \%$. After introduction of HF therapy with ACE-Is and beta-blockers, at least a partial recovery of LVEF was observed in $82 \%$ of patients who developed cardiotoxicity [166]. Integrated patient management according to 
Table 2. Cardiotoxicity of antineoplastic medications.

\begin{tabular}{|c|c|c|c|c|}
\hline $\begin{array}{l}\text { Class } \\
\text { Specific agents }\end{array}$ & $\begin{array}{l}\text { Cancer control } \\
\text { mechanism }\end{array}$ & Cardiovascular toxicities & Mechanism of cardiotoxicity & $\begin{array}{l}\text { Cardiovascular } \\
\text { treatment } \\
\text { considerations }\end{array}$ \\
\hline \multicolumn{5}{|l|}{ Anthracyclines } \\
\hline $\begin{array}{l}\text { Doxorubicin, idarubicin, } \\
\text { epirubicin, mitoxantrone }\end{array}$ & $\begin{array}{l}\text { DNA damage, lipid } \\
\text { peroxidation, p53 } \\
\text { activation, induction of } \\
\text { apoptosis in response to } \\
\text { topoisomerase II } \\
\text { inhibition }\end{array}$ & $\begin{array}{l}\text { HF and LVSD (3-48\%), bradycardia, } \\
\text { sinus tachycardia, atrioventricular } \\
\text { block, conduction disturbances, } \\
\text { AF, supraventricular tachycardias, } \\
\text { ventricular tachycardia/fibrillation, } \\
\text { acute pericarditis }\end{array}$ & $\begin{array}{l}\text { - DNA damage due to ROS } \\
\text { production } \\
\text { - Changes in iron metabolism } \\
\text { and calcium signaling } \\
\text { - Inhibition of topoisomerase } \\
2-\beta \text { in cardiomyocyte with } \\
\text { myocyte destruction }\end{array}$ & $\begin{array}{l}\text { ACE-Is/ARBs } \\
\text { BBs } \\
\text { Aldosterone antagonists } \\
\text { Statins } \\
\text { Sacubitril/valsartan }\end{array}$ \\
\hline
\end{tabular}

\section{Antimetabolites}

Cyclophosphamide, ifosfamide, cisplatin, melphalan
Induction of apoptosis due to interaction with DNA
$\mathrm{HF}$, bradycardia, atrioventricular block AF, supraventricular tachycardias, ventricular tachycardia/fibrillation, pulmonary veno-occlusive disease (cyclophosphamide), acute pericard $\mathrm{CAD}$ and ischemic stroke (cisplatin)
DNA damage due to ROS oduction and calcium signaling $2-\beta$ in cardiomyocyte with myocyte destruction

ACE-Is/ARBs

Statins

Sacubitril/valsartan

$\mathrm{N} / \mathrm{A}$

cive mitochondrial damage - GSTP deficiency - $\downarrow$ expression of heart fatty acid-binding protein and carnitine palmitoyltransferase - Platelet activation and aggregation

\section{Antimicrotubule agents}

Paclitaxel Inhibition of mitosis

Docetaxel
$\mathrm{HF}$, bradycardia, atrioventricular block, conduction disturbances, AF, supraventricular tachycardias, ventricular tachycardia/fibrillation (paclitaxel), ischemic stroke (paclitaxel)
Trastuzumab

ErbB2 inhibition

\begin{tabular}{ll} 
Pertuzumab & ErbB2 inhibition \\
\hline Bevacizumab & $\begin{array}{l}\text { VEGF inhibition in tumor } \\
\text { vasculature }\end{array}$
\end{tabular}

Killing CD20+ cells
HF and LVSD (1.7-20.1\%), arterial hypertension (4\%), arrhythmias, thromboembolic events (2-3\%)
HF and LVSD (0.7 - 1.2\%), thromboembolic events

Arterial hypertension (7.5\%), HF (1.6 - 4\%), CAD (3.8\%), arterial and venous thromboembolic events (3-21\%), thrombotic microangiopathy
- Impaired ErbB/Neuregulin-1activated pathway: $\downarrow$ cardiomyocyte function and survival

- Inhibition of Notch signaling: $\downarrow$ cell proliferation and cell survival

- Impaired intracellular antioxidant/oxidant balance - $\uparrow$ circulating angiotensin II

Similar to trastuzumab

- Disruption of VEGF-mediated endothelial dysfunction, oxidative treatment: ACE-Is). Avoid stress

- Loss of contractile function in cardiomyocyte

- $\uparrow$ arterial pressure

HF, CAD, Bradycardia, Atrioventricular block, Atrial Fibrillation, Ventricular tachycardia/fibrillation
Avoid concurrentand sequential administration of anthracycline; ACEIs and/or BBs if reduced LVEF

ACEIs and/or BBs if reduced LVEF nondihydropyridine calcium channel blockers ( $\uparrow$ levels of plasma bevacizumab due to cytochrome P450 3A4 inhibition) $\uparrow$ Cytokine release, particularly N/A IL-6 - Neurohormonal activation, excessive sympathetic stimulation and microvascular dysfunction - Treticulin fiber formation in cardiomyocytes, $\downarrow$ myocardial contractility and conduction

\section{VEGF inhibitor}

Cabozantinib, pazopanib, regorafenib, sorafenib, sunitinib, vandetanib
VEGF inhibition in tumor Arterial Hypertension, HF, QT vasculature prolongation $>500 \mathrm{~ms}$, Torsade de pointes (pazopanib, vandetanib), $\mathrm{CAD}$, Vasospasm (sorafenib), AF, thromboembolic events $\downarrow$ nitric oxide; microvascular rarefaction; $\uparrow$ endothelin-1
ACE-Is/ARBs; dihydropyridine calcium-channel blockers for hypertension

To be continued on next page 
Table 2. Continued from previous page.

\begin{tabular}{|c|c|c|c|c|}
\hline $\begin{array}{l}\text { Class } \\
\text { Specific agents }\end{array}$ & $\begin{array}{l}\text { Cancer control } \\
\text { mechanism }\end{array}$ & Cardiovascular toxicities & Mechanism of cardiotoxicity & $\begin{array}{l}\text { Cardiovascular } \\
\text { treatment } \\
\text { considerations }\end{array}$ \\
\hline
\end{tabular}

\begin{tabular}{|c|c|c|c|c|}
\hline $\begin{array}{l}\text { ALK inhibitors } \\
\text { Alectinib, crizotinib }\end{array}$ & $\begin{array}{l}\text { Inhibition of ALK activity: } \\
\downarrow \text { cell proliferation, } \\
\downarrow \text { angiogenesis }\end{array}$ & QT prolongation $>500 \mathrm{~ms}$, bradycardia & $\begin{array}{l}\downarrow \text { If (pacemaker current) in } \\
\text { sinoatrialnodal cells }\end{array}$ & Avoid nodal blockingagents \\
\hline $\begin{array}{l}\text { BTK inhibitors } \\
\text { Acalabrutinib, ibrutinib }\end{array}$ & $\begin{array}{l}\text { Inhibition of the BTK } \\
\text { pathway }\end{array}$ & $\begin{array}{l}\text { AF, ventricular arrhythmias; arterial } \\
\text { hypertension }\end{array}$ & $\begin{array}{l}\text { - Inhibition of cardiac PI3K-Akt } \\
\text { pathway } \\
\text { - Atrial fibrosis } \\
\text { - Dysregulated calcium handling }\end{array}$ & $\begin{array}{l}\text { Avoid drugs that interact } \\
\text { with the CYP } 3 \text { A4 system } \\
\text { and p -glycoprotein }\end{array}$ \\
\hline $\begin{array}{l}\text { BCR-ABL } \\
\text { Imatinib, nilotinib, } \\
\text { dasatinib, bosutinib } \\
\text { ponatinib }\end{array}$ & $\begin{array}{l}\text { Target BCR-ABL } \\
\text { fusionprotein, c-Kit, and } \\
\text { PDFG receptors }\end{array}$ & $\begin{array}{l}\text { CAD, HF, arterial hypertension; } \\
\text { QT prolongation; pulmonary } \\
\text { hypertension (nilotinib, dasatinib); } \\
\text { pleural effusion (imatinib, dasatinib); } \\
\text { pericarditis and pericardial effusion } \\
\text { (bosutinib); PAD (ponatinib, nilotinib); } \\
\text { thromboembolic events (ponatinib). }\end{array}$ & $\begin{array}{l}\text { - Accelerated atherosclerosis and } \\
\text { endothelial dysfunction } \\
\text { - Thrombotic microangiopathy } \\
\text { - Hyperlipidemia, hyperglycemia }\end{array}$ & Statins; antihyperglycemics \\
\hline $\begin{array}{l}\text { BRAF inhibitors } \\
\text { Dabrafenib, } \\
\text { Vemurafenib }\end{array}$ & $\begin{array}{l}\text { Selective inhibition of } \\
\text { B-raf which blockscellular } \\
\text { proliferation }\end{array}$ & $\begin{array}{l}\text { QT prolongation > } 500 \mathrm{~ms}(1.6 \%) \text {, } \\
\text { Torsade de pointes }\end{array}$ & $\begin{array}{l}\text { - Impaired VEGF signaling and } \\
\text { NO production } \\
\text { - Cardiomyocyte hypertrophy and } \\
\text { pathological remodeling }\end{array}$ & $\mathrm{N} / \mathrm{A}$ \\
\hline $\begin{array}{l}\text { MEK inhibitors } \\
\text { Binimetinib, } \\
\text { Combimetinib, } \\
\text { trametinib }\end{array}$ & $\begin{array}{l}\text { Allosteric inhibition of } \\
\text { MEK affecting the } \\
\text { MAPK pathway }\end{array}$ & $\begin{array}{l}\text { Arterial hypertension; myocardial } \\
\text { dysfunction and heart failure; } \\
\text { QT prolongation }\end{array}$ & $\begin{array}{l}\text { - Inhibition of ERK1/2 activation } \\
\text { in the heart } \\
\text { - Impaired VEGF signaling and } \\
\text { NO production } \\
\text { - Cardiomyocyte hypertrophy and } \\
\text { pathological remodeling }\end{array}$ & $\mathrm{N} / \mathrm{A}$ \\
\hline
\end{tabular}

$\begin{array}{ll}\text { Thalidomide } & -\uparrow \text { T cell proliferation } \\ & \text { and NK cell function, } \\ & \uparrow \text { IFN- } \gamma \text { and IL-2 levels, } \\ & \downarrow \text { production of } \\ & \text { pro-inflammatory } \\ & \text { cytokines (in particular } \\ & \text { TNF- } \alpha \text { ) } \\ & -\downarrow \text { angiogenesis } \\ \text { Lenalidomide } & \end{array}$

Bradycardia, atrioventricular block, arterial and venous thromboembolic events (8-22.5\%)

$\downarrow$ production of pro-inflammatory TNF- $\alpha$ )

Lenalidomide

Arterial and venous thromboembolic events (4-9\%), CAD (0-1.9\%), arterial hypertension (7-8\%), hypotension (7\%)
- Inhibition of TNF-expression and Aspirin or prophylactic activity leading to overactivity of LMWH may be considered the parasympathetic system (dorsal motor neurons of the vagus nerve)

- Endothelial cell injury and dysfunction, hypercoagulability

- Endothelial cell injury and dysfunction, hypercoagulability

Proteasome inhibitor:

\begin{tabular}{|c|c|c|}
\hline Carfilzomib & $\begin{array}{l}\text { Irreversible proteasome } \\
\text { inhibition by binding to } \\
\text { the catalytic site: } \\
\text { accumulation of damaged } \\
\text { and abnormal proteins }\end{array}$ & $\begin{array}{l}\text { HF (11-25\%), CAD, ventricular } \\
\text { tachycardia/fibrillation, arterial } \\
\text { hypertension (5-27\%), pulmonary } \\
\text { hypertension (1\%) }\end{array}$ \\
\hline
\end{tabular}

Immune checkpoint inhibitors (ICls)

PD-L1 inhibitors

Atezolizumab, avelumab

\section{PD-1 inhibitors}

Nivolumab,

pembrolizumab

\section{CTLA4 inhibitor}

Ipilimumab
Binding to host immunenegative regulation receptors involved in malignancy
Myocarditis, Pericarditis, Takotsubo cardiomyopathy, Dilated cardiomyopathy $-\downarrow$ eNOS activity and $\downarrow$ NO levels: Traditional heart failure impaired vasodilation, endothelial treatment

dysfunction, oxidative stress

- adverse effects on vascular smooth muscle: plaque instability

\section{Hormone therapy}

Aromatase inhibitors

Anastrozole, letrozole

\section{Inhibition of estrogen $\quad \mathrm{CAD}$, arterial hypertension,} synthesis in hormonedependent tumors thromboembolic events
- Molecular mimicry (shared
antigen between the tumor and
myocardium)

- Accelerated atherosclerosis
Corticosteroids; standard heart failure therapiesif reduced LVEF; in corticosteroid resistant myocarditis consider infliximab, intravenous immunoglobulin, plasmapheresis, abatacept, alemtuzumab, anti- thymocyte globulin, mycophenolate 
the cardio-oncology approach is promising and dedicated cardiooncology services have been developed across the globe. But despite the growing interest in this emerging field, there is a paucity of data about their structure, activity and impact of such clinics on patient care and clinical outcomes. In the 5-year real-world experience reported by Pareek et al. [164] from 128 cancer patients with LVSD referred to the cardio-oncology clinic, $88 \%$ of patients were deemed fit for continuation of cancer therapy after cardiovascular optimization, while an improvement of LVSD after 1 year of follow-up was observed in $94 \%$ of patients. Similarly, encouraging results have been reported by Kappel et al. [167].

On the basis of what has been reported, despite the absence of randomized evidence, the use of a multidisciplinary approach must be supported.

\section{Conclusions}

In recent decades we have witnessed significant progress in the therapy of CVD and Cancer. With increasing patient survival, it is now increasingly evident that these two apparently so distant diseases often share the same risk factors having generally a chronic inflammatory state as a unifying element. Seen from this perspective, preventive cardiology is of primary importance: controlling obesity, hypertension, dyslipidemia and diabetes, fighting against smoking, sedentary lifestyle, and the unhealthy diet in patients with cancer may prevent the onset of cardiotoxicity while in patients with CVD helps to prevent cancer. Given the epidemiological relevance of the two morbid conditions, a more stringent control of these risk factors is urgent for the health of the general population. A better collaboration between cardiologists, oncologists and primary care doctors can improve the understanding of this two-way relationship and adopt the most effective and safest prevention strategy.

\section{References}

1. Araújo F, Gouvinhas C, Fontes F, et al. Trends in cardiovascular diseases and cancer mortality in 45 countries from five continents (1980-2010). Eur J Prev Cardiol 2014;21:1004-17.

2. Banke A, Schou M, Videbæk L, et al. Incidence of cancer in patients with chronic heart failure:A long-term follow-up study. Eur J Heart Fail 2016;18:260-6.

3. Hasin T, Gerber Y, McNallan SM, et al. Patients with heart failure have an increased risk of incident cancer. J Am Coll Cardiol 2013;62:881-6.

4. Moliner P, Lupón J, de Antonio M, et al. Trends in modes of death in heart failure over the last two decades: less sudden death but cancer deaths on the rise. Eur J Heart Fail 2019;21:1259-66.

5. Armenian SH, Xu L, Ky B, et al. Cardiovascular disease among survivors of adult-onset cancer:A community-based retrospective cohort study. J Clin Oncol 2016;34:1122-30.

6. Sturgeon KM, Deng L, Bluethmann SM, et al. A populationbased study of cardiovascular disease mortality risk in US cancer patients. Eur Heart J 2019;40:3889-97.

7. Whiteman DC, Wilson LF. The fractions of cancer attributable to modifiable factors: A global review. Cancer Epidemiol 2016;44:203-21.

8. Westerink NL, Nuver J, Lefrandt JD, et al. Cancer treatment induced metabolic syndrome:Improving outcome with lifestyle. Crit Rev Oncol Hematol 2016;108:128-36.

9. Lohmann AE, Ennis M, Taylor SK, et al. Metabolic factors, anthropometric measures, diet, and physical activity in longterm breast cancer survivors: change from diagnosis and comparison to non-breast cancer controls. Breast Cancer Res Treat 2017;164:451-60.

10. Coussens LM, Werb Z. Inflammation and cancer. Nature 2002;420:860-7.

Table 3. Management strategies according to Royal Brompton Hospital myocardial toxicity class.

\begin{tabular}{|c|c|c|c|c|}
\hline \multicolumn{2}{|c|}{ Cardiotoxicity group } & \multirow{2}{*}{$\begin{array}{l}\text { Classification } \\
\text { New BNP or troponin I rise but with } \\
\text { normal cardiac imaging (If normal at } \\
\text { baseline, then any increase above the } \\
\text { upper limit of normal. If abnormal at } \\
\text { baseline, then } 20 \% \text { rise). }\end{array}$} & \multirow{2}{*}{$\begin{array}{l}\text { Definition } \\
\text { Oncology therapy } \\
\text { Continue }\end{array}$} & \multirow{2}{*}{$\begin{array}{l}\text { Management strategies } \\
\text { Cardiology therapy } \\
\text { Cardio-oncology review. } \\
\text { Consider closer monitoring, or start low-dose } \\
\text { ACE-Is or BBs cardioprotection. }\end{array}$} \\
\hline 1 & $\begin{array}{l}\text { Early biochemical } \\
\text { cardiotoxicity }\end{array}$ & & & \\
\hline 2 & $\begin{array}{l}\text { Early functional } \\
\text { cardiotoxicity }\end{array}$ & $\begin{array}{l}\text { New reduction in GLS or grade III-IV } \\
\text { diastolic dysfunction and normal } \\
\text { biomarkers. }\end{array}$ & Continue & $\begin{array}{l}\text { Cardio-oncology review. } \\
\text { Consider closer monitoring, or start low-dose } \\
\text { ACE-Is or BBs cardioprotection. }\end{array}$ \\
\hline 3 & $\begin{array}{l}\text { Early mixed } \\
\text { cardiotoxicity }\end{array}$ & $\begin{array}{l}\text { Normal LVEF with abnormal biomarkers } \\
\text { and GLS/diastolic dysfunction. }\end{array}$ & Continue & $\begin{array}{l}\text { Cardio-oncology review. } \\
\text { Start low-dose ACE-Is or BBs cardioprotection. }\end{array}$ \\
\hline 4 & Symptomatic HFpEF & Symptomatic HFpEF. & $\begin{array}{l}\text { Interrupt and review } \\
\text { risk/benefit* }\end{array}$ & $\begin{array}{l}\text { Cardio-oncology review.Diuretic for fluid } \\
\text { congestion. } \\
\text { ACE-Is or BBs cardioprotection if continuing } \\
\text { cancer therapy. }\end{array}$ \\
\hline 5 & Asymptomatic LVSD & $\begin{array}{l}\text { New LVEF reduction to }<50 \% \text {, or a } \\
\text { reduction in } \mathrm{LVEF}>10 \% \text { to a } \mathrm{LVEF}<55 \% \S \text {. }\end{array}$ & $\begin{array}{l}\text { Review and balance } \\
\text { risk/benefit* }\end{array}$ & $\begin{array}{l}\text { Cardio-oncology review. } \\
\text { Start ACE-Is and/or BBs and up-titrate to } \\
50-100 \% \text { target dose for HF as tolerated. }\end{array}$ \\
\hline 6 & Symptomatic LVSD & $\begin{array}{l}\text { Symptomatic reduction in } \mathrm{LVEF}<50 \% \text {, } \\
\text { or a reduction in } \mathrm{LVEF}>10 \% \text { to a } \mathrm{LVEF} \\
<55 \% \S \text {. }\end{array}$ & $\begin{array}{l}\text { Interrupt and review } \\
\text { risk/benefit* }\end{array}$ & $\begin{array}{l}\text { Cardio-oncology review. } \\
\text { Start ACE-Is and/or BBs and up-titrate to 100\% } \\
\text { target dose for HF as tolerated }{ }^{\ddagger} \text {. }\end{array}$ \\
\hline
\end{tabular}

BNP, brain natriuretic peptide; ACE-Is, angiotensin-converting enzyme inhibitors; BBs, Beta-blockers; GLS, global longitudinal strain; LVEF, left ventricular ejection fraction; HFpEF, heart failure with preserved ejection fraction; LVSD, left ventricular systolic dysfunction. ${ }^{*}$ Continuing cardiotoxic cancer therapy may be suitable in selected cases depending on the risk/benefit ratio, severity of left ventricular impairment, symptoms, cancer stage and response. ${ }^{\$}$ If LVEF fall is to $>50 \%$, then incorporate either biomarker elevation or GLS reduction $(<-18 \%$ if normal at baseline, or $<15 \%$ relative reduction of GLS if reduced at baseline) 
11. Libby P. Inflammation and cardiovascular disease mechanisms1-3. Am J Clin Nutr 2006;83:S456-60.

12. Koene RJ, Prizment AE, Blaes A, et al. Shared risk factors in cardiovascular disease and cancer. Circulation 2016;32:900-7.

13. Frostegård J. Immunity, atherosclerosis and cardiovascular disease. BMC Med 2013;11:117.

14. Ross R. Atherosclerosis - An inflammatory disease. N Engl J Med 1999;340:115-26.

15. Masoudkabir F, Sarrafzadegan N, Gotay C, et al. Cardiovascular disease and cancer:Evidence for shared disease pathways and pharmacologic prevention. Atherosclerosis 2017;263:343-51.

16. Pateras I, Giaginis C, Tsigris $\mathrm{C}$, et al. NF- $\kappa \mathrm{B}$ signaling at the crossroads of inflammation and atherogenesis:Searching for new therapeutic links. Expert Opin Ther Targets 2014;18:1089-101.

17. Mouton AJ, Li X, Hall ME, et al. Obesity, hypertension, and cardiac dysfunction: novel roles of immunometabolism in macrophage activation and inflammation. Circ Res 2020;126:789-806.

18. Rauchhaus M, Doehner W, Francis DP, et al. Plasma cytokine parameters and mortality in patients with chronic heart failure. Circulation 2000;102:3060-7.

19. Balkwill F, Mantovani A. Inflammation and cancer: Back to Virchow? Lancet 2001;357:539-45.

20. Suarez-Carmona M, Lesage J, Cataldo D, et al. EMT and inflammation:inseparable actors of cancer progression. Mol Oncol 2017;11:805-23.

21. de Sanjose S, Quint WGV, Alemany L, et al. Human papillomavirus genotype attribution in invasive cervical cancer:a retrospective cross-sectional worldwide study. Lancet Oncol 2010;11:1048-56.

22. Huang JQ, Sridhar S, Chen Y, et al. Meta-analysis of the relationship between Helicobacter pylori seropositivity and gastric cancer. Gastroenterology 1998;114:1169-79.

23. Thorley-Lawson DA, Gross A. Persistence of the Epstein-Barr Virus and the Origins of associated lymphomas. N Engl J Med 2004;350:1328-37.

24. Woodward J. Improving outcomes of refractory celiac disease - Current and emerging treatment strategies. Clin Exp Gastroenterol 2016;9:225-36.

25. Wu Y, Antony S, Meitzler JL, et al. Molecular mechanisms underlying chronic inflammation-associated cancers. Cancer Lett 2014;345:164-73.

26. Bent R, Moll L, Grabbe S, et al. Interleukin-1 beta - A friend or foe in malignancies? Int J Mol Sci 2018;19:1-34.

27. Awan Z, Genest J. Inflammation modulation and cardiovascular disease prevention. Eur J Prev Cardiol 2015;22:719-33.

28. Kundu JK, Surh YJ. Emerging avenues linking inflammation and cancer. Free Radic Biol Med 2012;52:2013-37.

29. Grumbach IM. Cardio-oncology at the beginning of a new decade. J Am Heart Assoc 2020;9:e015890.

30. Ledard N, Liboz A, Blondeau B, et al. Slug, a cancer-related transcription factor, is involved in vascular smooth muscle cell transdifferentiation induced by platelet-derived growth factor-BB during atherosclerosis. J Am Heart Assoc 2020;9:e014276.

31. Blaes A, Prizment A, Koene RJ, et al. Cardio-oncology related to heart failure: common risk factors between cancer and cardiovascular disease. Heart Fail Clin 2017;13:367-80.

32. Murphy SP, Kakkar R, McCarthy CP, et al. Inflammation in Heart Failure: JACC State-of-the-Art Review. J Am Coll Cardiol 2020;75:1324-40.

33. Tanaka T, Narazaki M, Kishimoto T. Il-6 in inflammation, immunity, and disease. Cold Spring Harb Perspect Biol 2014;6:a016295.

34. Yao X, Huang J, Zhong H, et al. Targeting interleukin-6 in inflammatory autoimmune diseases and cancers. Pharmacol Ther 2014;141:125-39.

35. Singh-Manoux A, Shipley MJ, Bell JA, et al. Association between inflammatory biomarkers and all-cause, cardiovascular and cancer-related mortality. CMAJ 2017;189:384-90.

36. Aboumsallem JP, Moslehi J, de Boer RA. Reverse cardiooncology: cancer development in patients with cardiovascular disease. J Am Heart Assoc 2020;9:e013754.

37. Wolin KY, Carson K, Colditz GA. Obesity and cancer. Oncologist 2010;15:556-65.

38. De Gonzalez AB, Hartge P, Cerhan JR, et al. Body-mass index and mortality among 1.46 million white adults. N Engl J Med 2010;363:2211-9.

39. Johnson CB, Davis MK, Law A, et al. Shared Risk factors for cardiovascular disease and cancer: implications for preventive health and clinical care in oncology patients. Can J Cardiol 2016;32:900-7.

40. Sjöström L, Narbro K, Sjöström CD, et al. Effects of bariatric surgery on mortality in Swedish obese subjects. N Engl J Med 2007;357:741-52.

41. Stampfer M, Jahn JL. Partnerships for promoting prevention. Circulation 2013;127:1267-9.

42. Sung H, Siegel RL, Rosenberg PS, et al. Emerging cancer trends among young adults in the USA:analysis of a population-based cancer registry. Lancet Public Heal 2019;4:e137-47.

43. Brenner DR, Ruan Y, Shaw E, et al. Increasing colorectal cancer incidence trends among younger adults in Canada. Prev Med (Baltim) 2017;105:345-9.

44. Berger NA. Young adult cancer: influence of the obesity pandemic. Obesity 2018;26:641-650.

45. Liu PH, Wu K, Ng K, et al. Association of obesity with risk of early-onset colorectal cancer among women. JAMA Oncol 2019;5:37-44.

46. Bays HE. Adiposopathy:Is 'sick fat' a cardiovascular disease? J Am Coll Cardiol 2011;57:2461-73.

47. Neeland IJ, Poirier P, Després JP. Cardiovascular and metabolic heterogeneity of obesity: clinical challenges and implications for management. Circulation 2018;137:1391-406.

48. Grundy SM. Obesity, metabolic syndrome, and coronary atherosclerosis. Circulation 2002;105:2696-8.

49. Chait A, den Hartigh LJ. Adipose tissue distribution, inflammation and its metabolic consequences, including diabetes and cardiovascular disease. Front Cardiovasc Med 2020;7:1-41.

50. Mechanick JI, Farkouh ME, Newman JD, et al. Cardiometabolic-based chronic disease, adiposity and dysglycemia drivers: JACC state-of-the-art review. J Am Coll Cardiol 2020. doi: 10.1016/j.jacc.2019.11.044.

51. Piepoli MF, Hoes AW, Agewall S, et al. 2016 European guidelines on cardiovascular disease prevention in clinical practice. Eur Heart J 2016;37:2315-81.

52. Eckel RH, Krauss RM. American Heart Association call to action: Obesity as a major risk factor for coronary heart disease. Circulation 1998;97:2099-100.

53. Dikaiou P, Björck L, Adiels M, et al. Obesity, overweight and risk for cardiovascular disease and mortality in young women. Eur J Prev Cardiol 2020. doi: 10.1177/204748732090898310.

54. Gérard C, Brown KA. Obesity and breast cancer - Role of estrogens and the molecular underpinnings of aromatase regulation in breast adipose tissue. Mol Cell Endocrinol 2018;466:15-30.

55. Martin SS, Qasim A, Reilly MP. Leptin resistance. A possible 
interface of inflammation and metabolism in obesity-related cardiovascular disease. J Am Coll Cardiol 2008;52:1201-10.

56. Ghasemi A, Saeidi J, Azimi-Nejad M, et al. Leptin-induced signaling pathways in cancer cell migration and invasion. Cell Oncol 2019;42:243-60.

57. Stefanou N, Papanikolaou V, Furukawa Y, et al. Leptin as a critical regulator of hepatocellular carcinoma development through modulation of human telomerase reverse transcriptase. BMC Cancer 2010;10:442.

58. Alshaker H, Sacco K, Alfraidi A, et al. Leptin signalling, obesity and prostate cancer:Molecular and clinical perspective on the old dilemma. Oncotarget 2015;6:35556-63.

59. Crean-Tate KK, Reizes O. Leptin regulation of cancer stem cells in breast and gynecologic cancer. Endocrinology 2018;159:3069-80.

60. Pollak M. The insulin and insulin-like growth factor receptor family in neoplasia:An update. Nat Rev Cancer 2012;12:159-69.

61. Mendonça FM, De Sousa FR, Barbosa AL, et al. Metabolic syndrome and risk of cancer:Which link? Metabolism 2015;64:182-9.

62. Gallagher EJ, LeRoith D. Obesity and diabetes:The increased risk of cancer and cancer-related mortality. Physiol Rev 2015;95:727-48.

63. Shah MS, Brownlee M. Molecular and cellular mechanisms of cardiovascular disorders in diabetes. Circ Res 2016;118:1808-29.

64. King GL, Goodman AD, Buzney S, et al. Receptors and growth-promoting effects of insulin and insulin-like growth factors on cells from bovine retinal capillaries and aorta. J Clin Invest 1985;75:1028-36.

65. Giovannucci E, Harlan DM, Archer MC, et al. Diabetes and cancer: A consensus report. Diabetes Care 2010;33:1674-85.

66. Roddam AW, Allen NE, Appleby P, et al. Insulin-like growth factors, their binding proteins, and prostate cancer risk:Analysis of individual patient data from 12 prospective studies. Ann Intern Med 2008;149:461-71.

67. Renehan AG, Zwahlen M, Minder C, et al. Insulin-like growth factor (IGF)-I, IGF binding protein-3, and cancer risk:systematic review and meta-regression analysis. Lancet 2004;363:1346-53.

68. Powell DR, Suwanichkul A, Cubbage ML, et al. Insulin inhibits transcription of the human gene for insulin-like growth factor-binding protein-1. J Biol Chem 1991;266:18868-76.

69. Calle EE, Kaaks R. Overweight, obesity and cancer:Epidemiological evidence and proposed mechanisms. Nat Rev Cancer 2004;4:579-91.

70. Shoelson SE, Lee J, Goldfine AB. Inflammation and insulin resistance. J Clin Invest 2006;116:1793-801.

71. Ference BA, Ginsberg HN, Graham I, et al. Low-density lipoproteins cause atherosclerotic cardiovascular disease. 1. Evidence from genetic, epidemiologic, and clinical studies. A consensus statement fromthe European Atherosclerosis Society Consensus Panel. Eur Heart J 2017;38:2459-72.

72. Alexander RW. Hypertension and the pathogenesis of atherosclerosis. Hypertension 1995;25:155-61.

73. Warns J, Marwarha G, Freking N, et al. 27-hydroxycholesterol decreases cell proliferation in colon cancer cell lines. Biochimie 2018; 153:171-80.

74. Nelson ER, Wardell SE, Jasper JS, et al. 27Hydroxycholesterol links hypercholesterolemia and breast cancer pathophysiology. Science 2013;342:1094-8.

75. Raza S, Meyer M, Goodyear C, et al. The cholesterol metabolite 27-hydroxycholesterol stimulates cell proliferation via ER $\beta$ in prostate cancer cells. Cancer Cell Int 2017;17:52.
76. Umetani M, Ghosh P, Ishikawa $\mathrm{T}$, et al. The cholesterol metabolite 27-hydroxycholesterol promotes atherosclerosis via proinflammatory processes mediated by estrogen receptor alpha. Cell Metab 2014;20:172-82.

77. Kang YS, Park YG, Kim BK, et al. Angiotensin II stimulates the synthesis of vascular endothelial growth factor through the p38 mitogen activated protein kinase pathway in cultured mouse podocytes. J Mol Endocrinol 2006;36:377-88.

78. Ferrara N. VEGF and the quest for tumour angiogenesis factors. Nat Rev Cancer 2002;2:795-803.

79. Stocks T, Van Hemelrijck M, Manjer J, et al. Blood pressure and risk of cancer incidence and mortality in the metabolic syndrome and cancer project. Hypertension 2012;59:802-10.

80. Tini G, Sarocchi M, Tocci G, et al. Arterial hypertension in cancer: The elephant in the room. Int J Cardiol 2019;281:133-9.

81. Grossman E, Messerli FH, Boyko V, et al. Is there an association between hypertension and cancer mortality? Am J Med 2002;112:479-86.

82. Morris PB, Ference BA, Jahangir E, et al. Cardiovascular effects of exposure to cigarette smoke and electronic cigarettes: clinical perspectives from the Prevention of Cardiovascular Disease Section Leadership Council and Early Career Councils of the American College of Cardiology. J Am Coll Cardiol 2015;66:1378-91.

83. Secretan B, Straif K, Baan R, et al. A review of human carcinogens--Part E: tobacco, areca nut, alcohol, coal smoke, and salted fish. Lancet Oncol 2009;10:1033-4.

84. Carter BD, Abnet CC, Feskanich D, et al. Smoking and mortality-beyond established causes. N Engl J Med 2015;372: 631-40.

85. Bing RJ. Cardiac metabolism: Its contributions to alcoholic heart disease and myocardial failure. Circulation 1978;58:965-70.

86. Boffetta P, Hashibe M. Alcohol and cancer. Lancet Oncol 2006;7:149-56.

87. Bagnardi V, Rota M, Botteri E, et al. Light alcohol drinking and cancer: A meta-analysis. Ann Oncol 2013;24:301-8.

88. Tsukuma H, Hiyama T, Tanaka S, et al. Risk Factors for hepatocellular carcinoma among patients with chronic liver disease. N Engl J Med 1993;328:1797-801.

89. Boyle P, Autier P, Bartelink H, et al. European code against cancer and scientific justification: Third version (2003). Ann Oncol 2003;14:973-1005.

90. World Cancer Research Fund/American Institute for Cancer Research. Continuous Update Project Expert Report 2018. Alcoholic drinks and the risk of cancer. Available from: http://www.dietandcancerreport.org

91. Puddu PE, Shivappa N, Menotti A, et al. Energy-adjusted dietary inflammatory index scores predict long-term cardiovascular disease mortality and other causes of death in an ecological analysis of the Seven Countries Study. Eur J Prev Cardiol 2020. doi: 10.1177/2047487320903866.

92. Li Y, Hruby A, Bernstein AM, et al. Saturated fats compared with unsaturated fats and sources of carbohydrates in relation to risk of coronary heart disease. A prospective cohort study. $\mathrm{J}$ Am Coll Cardiol 2015;66:1538-48.

93. MacMahon S, Duffy S, Rodgers A, et al. Blood cholesterol and vascular mortality by age, sex, and blood pressure:A meta-analysis of individual data from 61 prospective studies with 55000 vascular deaths. Lancet 2007;370:1829-39.

94. Islam MA, Amin MN, Siddiqui SA, et al. Trans fatty acids and lipid profile: A serious risk factor to cardiovascular disease, cancer and diabetes. Diabetes Metab Syndr Clin Res Rev 2019;13:1643-7. 
95. Aune D, Giovannucci E, Boffetta P, et al. Fruit and vegetable intake and the risk of cardiovascular disease, total cancer and all-cause mortality-A systematic review and doseresponse meta-analysis of prospective studies. Int J Epidemiol 2017;46:1029-56.

96. Wu H, Flint AJ, Qi Q, et al. Whole grain intake and mortality: Two large prospective studies in U.S. men and women. JAMA Intern Med 2015;175:373-84.

97. Lampe JW. Health effects of vegetables and fruit:Assessing mechanisms of action in human experimental studies. Am J Clin Nutr 1999;70:S475-90.

98. Anderson JW, Baird P, Davis RH, et al. Health benefits of dietary fiber. Nutr Rev 2009;67:188-205.

99. Toledo E, Salas-Salvado J, Donat-Vargas C, et al. Mediterranean diet and invasive breast cancer risk among women at high cardiovascular risk in the predimed trial a randomized clinical trial. JAMA Intern Med 2015;175: $1752-60$

100. Chlebowski RT, Aragaki AK, Anderson GL, et al. Dietary modification and breast cancer mortality: long-term followup of the Women's Health Initiative randomized trial. J Clin Oncol 2020. doi:10.1200/jco.19.00435.

101. Samitz G, Egger M, Zwahlen M. Domains of physical activity and all-cause mortality:Systematic review and doseresponse meta-analysis of cohort studies. Int $\mathrm{J}$ Epidemiol 2011;40:1382-400.

102. Peteiro J, Bouzas-Mosquera A, Pertega S, et al. Prediction of cardiovascular, cancer and non-cardiovascular non-cancer death by exercise echocardiography. Eur J Prev Cardiol 2019. doi: 10.1177/2047487319869692.

103. Sofi F, Capalbo A, Cesari F, et al. Physical activity during leisure time and primary prevention of coronary heart disease:An updated meta-analysis of cohort studies. Eur J Cardiovasc Prev Rehabil 2008;15:247-257.

104. Sattelmair J, Pertman J, Ding EL, et al. Dose response between physical activity and risk of coronary heart disease: A meta-analysis. Circulation 2011;124:789-95.

105. Pandey A, Garg S, Khunger M, et al. Dose-response relationship between physical activity and risk of heart failure: A meta-analysis. Circulation 2015;132:1786-94.

106. Hu FB, Willett WC, Li T, et al. Adiposity as compared with physical activity in predicting mortality among women. N Engl J Med 2004;351:2694-703.

107. Kodama S, Saito K, Tanaka S, et al. Cardiorespiratory fitness as a quantitative predictor of all-cause mortality and cardiovascular events in healthy men and women: A metaanalysis. JAMA 2009;301:2024-35.

108. Schnohr P, Lange P, Scharling H, et al. Long-term physical activity in leisure time and mortality from coronary heart disease, stroke, respiratory diseases, and cancer. The Copenhagen City Heart Study. Eur J Cardiovasc Prev Rehabil 2006;13:173-9.

109. Wen CP, Wai JPM, Tsai MK, et al. Minimum amount of physical activity for reduced mortality and extended life expectancy: A prospective cohort study. Lancet 2011;378: 1244-53.

110. Hasin T, Gerber Y, Weston SA, et al. Heart failure after myocardial infarction is associated with increased risk of cancer. J Am Coll Cardiol 2016;68:265-71.

111. Hasin T, Iakobishvili Z, Weisz G. Associated risk of malignancy in patients with cardiovascular disease: Evidence and possible mechanism. Am J Med 2017;130:780-7.

112. Arslan F, De Kleijn DP, Pasterkamp G. Innate immune sig- naling in cardiac ischemia. Nat Rev Cardiol 2011;8:292-300.

113. Ordovás JM, Smith CE. Epigenetics and cardiovascular disease. Nat Rev Cardiol 2010;7:510-9.

114. Qureshi AI, Malik AA, Saeed O, et al. Incident cancer in a cohort of 3,247 cancer diagnosis free ischemic stroke patients. Cerebrovasc Dis 2015;39:262-8.

115. Jaiswal S, Natarajan P, Silver AJ, et al. Clonal hematopoiesis and risk of atherosclerotic cardiovascular disease. N Engl J Med 2017;377:111-21.

116. Bangalore S, Kumar S, Kjeldsen SE, et al. Antihypertensive drugs and risk of cancer: Network meta-analyses and trial sequential analyses of 324168 participants from randomised trials. Lancet Oncol 2011;12:65-82.

117. Dai YN, Wang JH, Zhu JZ, et al. Angiotensin-converting enzyme inhibitors/angiotensin receptor blockers therapy and colorectal cancer: a systematic review and meta-analysis. Cancer Causes Control 2015;26:1245-55.

118. Ganz PA, Habel LA, Weltzien EK, et al. Examining the influence of beta blockers and ACE inhibitors on the risk for breast cancer recurrence: Results from the LACE cohort. Breast Cancer Res Treat 2011;129:549-56.

119. Holden SE, Jenkins-Jones S, Morgan CL, et al. Glucoselowering with exogenous insulin monotherapy in type 2 diabetes: Dose association with all-cause mortality, cardiovascular events and cancer. Diabetes Obes Metab 2015;17: 350-62.

120. Mast ME, Heijenbrok MW, Petoukhova AL, et al. Preradiotherapy calcium scores of the coronary arteries in a cohort of women with early-stage breast cancer: A comparison with a cohort of healthy women. Int J Radiat Oncol Biol Phys 2012;83:853-8.

121. Blann AD, Dunmore S. Arterial and venous thrombosis in cancer patients. Cardiol Res Pract 2011;2011:394740.

122. Hisada Y, Mackman N. Cancer-associated pathways and biomarkers of venous thrombosis. Blood 2017;130:1499-506.

123. Albini A, Pennesi G, Donatelli F, et al. Cardiotoxicity of anticancer drugs: The need for cardio-oncology and cardiooncological prevention. J Natl Cancer Inst 2010;102:14-25.

124. Brana I, Tabernero J. Cardiotoxicity. Ann Oncol 2010;21:173-9.

125. Yeh ETH, Tong AT, Lenihan DJ, et al. Cardiovascular complications of cancer therapy: diagnosis, pathogenesis, and management. Circulation 2004;109:3122-31.

126. Lloyd-Jones DM, Hong Y, Labarthe D, et al. Defining and setting national goals for cardiovascular health promotion and disease reduction: The american heart association's strategic impact goal through 2020 and beyond. Circulation 2010;121:586-613.

127. Lachman S, Peters RJG, Lentjes MAH, et al. Ideal cardiovascular health and risk of cardiovascular events in the EPIC-Norfolk prospective population study. Eur J Prev Cardiol 2015;23:986-94.

128. Folsom AR, Yatsuya H, Nettleton JA, et al. Community prevalence of ideal cardiovascular health, by the american heart association definition, and relationship with cardiovascular disease incidence. J Am Coll Cardiol 2011;57:1690-6.

129. Rasmussen-Torvik LJ, Shay CM, Abramson JG, et al. Ideal cardiovascular health is inversely associated with incident cancer the atherosclerosis risk in communities study. Circulation 2013;127:1270-5.

130. Barac A, Murtagh G, Carver JR, et al. Cardiovascular health of patients with cancer and cancer survivors:A roadmap to the next level. J Am Coll Cardiol 2015;65:2739-46. 
131. Giza DE, Marmagkiolis K, Mouhayar E, et al. Management of CAD in patients with active cancer: the interventional cardiologists' perspective. Curr Cardiol Rep 2017;19:1-10.

132. Bharadwaj AS, Swamy PM, Mamas MA. Outcomes of percutaneous coronary interventions in cancer patients. Expert Rev Cardiovasc Ther 2020;18:25-32.

133. Balanescu SM, Balanescu DV, Donisan T, et al. The oncocardiologist dilemma: to implant, to defer, or to avoid transcatheter aortic valve replacement in cancer patients with aortic stenosis? Curr Cardiol Rep 2019;21:1-9.

134.Zamorano JL, Lancellotti P, Rodriguez Muñoz D, et al. 2016 ESC Position Paper on cancer treatments and cardiovascular toxicity developed under the auspices of the ESC Committee for Practice Guidelines. Eur Heart J 2016;37:2768-801.

135. Marvel FA, Whelton SP, Blumenthal RS. A cardio-oncology cardiovascular prevention framework. JACC CardioOncology 2019;1:252-5.

136. Lotrionte M, Biondi-Zoccai G, Abbate A, et al. Review and meta-analysis of incidence and clinical predictors of anthracycline cardiotoxicity. Am J Cardiol 2013;112:1980-4.

137. Mertens AC, Yasui Y, Neglia JP, et al. Late mortality experience in five-year survivors of childhood and adolescent cancer: The Childhood Cancer Survivor Study. J Clin Oncol 2001;19:3163-72.

138. Shah CP, Moreb JS. Cardiotoxicity due to targeted anticancer agents:a growing challenge. Ther Adv Cardiovasc Dis 2019;13:1-6.

139. Lenihan DJ, Fradley MG, Dent S, et al. Proceedings from the Global Cardio-Oncology Summit: The Top 10 Priorities to Actualize for CardioOncology. JACC CardioOncology 2019; $1: 256-72$.

140. Guha A, Armanious M, Fradley MG. Update on cardiooncology: Novel cancer therapeutics and associated cardiotoxicities. Trends Cardiovasc Med 2019;29:29-39.

141. Madeddu C, Deidda M, Piras A, et al. Pathophysiology of cardiotoxicity induced by nonanthracycline chemotherapy. J Cardiovasc Med 2016;17:e12-8.

142. Palaskas N, Lopez-Mattei J, Durand JB, et al. Immune checkpoint inhibitor myocarditis:pathophysiological characteristics, diagnosis, and treatment. J Am Heart Assoc 2020;9:e013757.

143. Maurea N, Coppola C, Piscopo G, et al. Pathophysiology of cardiotoxicity from target therapy and angiogenesis inhibitors. J Cardiovasc Med 2016;17:e19-26.

144. Foglietta J, Inno A, de Iuliis F, et al. Cardiotoxicity of aromatase inhibitors in breast cancer patients. Clin Breast Cancer 2017; 17:11-7.

145. Lee DH, Fradley MG. Cardiovascular complications of multiple myeloma treatment:evaluation, management, and prevention. Curr Treat Options Cardiovasc Med 2018;20:1-14.

146. Giza DE, Iliescu G, Hassan S, et al. Cancer as a risk factor for cardiovascular disease. Curr Oncol Rep 2017;19:1-8.

147. Gunaldi M, Duman BB, Afsar CU, et al. Risk factors for developing cardiotoxicity of trastuzumab in breast cancer patients:An observational single-centre study. J Oncol Pharm Pract 2016;22:242-7.

148. Brown SA, Okwuosa TM, Barac A, et al. The role of angiotensin-converting enzyme inhibitors and $\beta$-blockers in primary prevention of cardiac dysfunction in breast cancer patients. J Am Heart Assoc 2020;9:e015327.

149. Sarocchi M, Arboscello E, Ghigliotti G, et al. Ivabradine in Cancer Treatment-Related Left Ventricular Dysfunction. Chemotherapy 2019;63:315-20.
150. Sheppard CE, Anwar M. The use of sacubitril/valsartan in anthracycline-induced cardiomyopathy: A mini case series. J Oncol Pharm Pract 2019;25:1231-4.

151. Mach F, Baigent C, Catapano AL, et al. 2019 ESC/EAS Guidelines for the management of dyslipidaemias:Lipid modification to reduce cardiovascular risk. Eur Heart J 2020;41:111-88.

152.Zhong S, Zhang X, Chen L, et al. Statin use and mortality in cancer patients:Systematic review and meta-analysis of observational studies. Cancer Treat Rev 2015;41:554-67.

153. Jeong GH, Lee KH, Kim JY, et al. Statin and cancer mortality and survival: An umbrella systematic review and metaanalysis. J Clin Med 2020;9:1-17.

154. Shin S, Wook Shin D, Young Cho I, et al. Status of dyslipidemia management and statin undertreatment in Korean cancer survivors: A Korean National Health and Nutrition Examination Survey study. Eur J Prev Cardiol 2020. doi: 10.1177/2047487320905722.

155.Jeong SM, Shin DW, Cho J. Rates of underuse of statins among cancer survivors versus controls: NHANES 20112016. J Cancer Surviv 2020. doi: 10.1007/s11764-02000865-z.

156. Petrera M, Paleari L, Clavarezza M, et al. The ASAMET trial: A randomized, phase II, double-blind, placebo-controlled, multicenter, $2 \times 2$ factorial biomarker study of tertiary prevention with low-dose aspirin and metformin in stage I-III colorectal cancer patients. BMC Cancer 2018;18:1-9.

157. Joharatnam-Hogan N, Cafferty F, Hubner R, et al. Aspirin as an adjuvant treatment for cancer:feasibility results from the Add-Aspirin randomised trial. Lancet Gastroenterol Hepatol 2019;4:854-62.

158. Camara Planek MI, Silver AJ, Volgman AS, et al. Exploratory review of the role of statins, colchicine, and aspirin for the prevention of radiation-associated cardiovascular disease and mortality. J Am Heart Assoc 2020;9: e014668.

159. D'Ascenzi F, Anselmi F, Fiorentini C, et al. The benefits of exercise in cancer patients and the criteria for exercise prescription in cardio-oncology. Eur J Prev Cardiol 2019. doi: $10.1177 / 2047487319874900$.

160. Howden EJ, Bigaran A, Beaudry R, et al. Exercise as a diagnostic and therapeutic tool for the prevention of cardiovascular dysfunction in breast cancer patients. Eur J Prev Cardiol 2019;26:305-315.

161. Vainshelboim B, Chan K, Chen Z, et al. Cardiorespiratory fitness and cancer in men with cardiovascular disease: Analysis from the Veterans Exercise Testing Study. Eur J Prev Cardiol 2020. doi: 10.1177/2047487320916595.

162. Sanz-de la Garza M, Sitges M. Physical exercise: Another tool in the fight against cancer and its treatment side effects? Eur J Prev Cardiol 2019. doi: 10.1177/ 2047487319890173.

163. Murphy AC, Koshy AN, Mousley J, et al. Efficacy of mobile health cardiovascular risk-reduction strategies in cancer survivors. Eur J Prev Cardiol 2020. doi: 10.1177/ 2047487320907548.

164. Pareek N, Cevallos J, Moliner P, et al. Activity and outcomes of a cardio-oncology service in the United Kingdom-a five-year experience. Eur J Heart Fail 2018;20:1721-31.

165. Bosch X, Rovira M, Sitges M, et al. Enalapril and Carvedilol for preventing chemotherapy-induced left ventricular systolic dysfunction in patients with malignant hemopathies: 
The OVERCOME trial (preventiOn of Left Ventricular Dysfunction With Enalapril and caRvedilol in Patients Submitted to Intensive ChemOtherapy for the Treatment of Malignant hEmopathies). J Am Coll Cardiol 2013;61: 2355-62.

166. Cardinale D, Colombo A, Bacchiani G, et al. Early detection of anthracycline cardiotoxicity and improvement with heart failure therapy. Circulation 2015;131:1981-8.

167. Kappel C, Rushton M, Johnson C, et al. Clinical experience of patients referred to a multidisciplinary cardio-oncology clinic: An observational cohort study. Curr Oncol 2019;26:e322-7. 